\title{
ESTUDO DE CASO SOBRE OS ASPECTOS ECONÔMICOS DO ARTESANATO DA ASSOCIAÇÃO DOS ARTESÃOS DA FEIRA DE ARTESANATO - FEART, EM JUAZEIRO DO NORTE - CEARÁ
}

\author{
Ana Maria Pereira dos Santos ${ }^{1}$ \\ Romênia Oliveira de Souza²
}

\begin{abstract}
RESUMO
O artesanato ocupa um lugar de destaque no âmbito das atividades econômicas. A atividade artesanal apresenta-se como fonte de emprego e renda para mais de 8,5 milhões de pessoas no Brasil, e movimenta cerca de 28 bilhões de reais ou 2,8\% do Produto Interno Bruto (PIB) do país. A atividade artesanal além de trazer melhorias nas condições de vida dos artesãos contribui para o desenvolvimento econômico local de cada região. $\mathrm{O}$ artesanato está ligado à riqueza cultural bem como a uma forte vinculação com o setor turístico. O presente trabalho fornecerá informações sobre o tema: Aspectos Econômicos do Artesanato de Juazeiro do Norte-CE: o caso da associação dos artesãos da FEART. O mesmo tem como objetivo principal mostrar de que forma a FEART contribui para o fortalecimento e desenvolvimento do setor artesanal em Juazeiro do Norte-CE, e como objetivos específicos: caracterizar o setor artesanal e sua possível contribuição para o processo de desenvolvimento local; sintetizar o comportamento do setor artesanal no Brasil e suas contribuições econômicas; e identificar as contribuições da FEART para o desenvolvimento do setor artesanal em Juazeiro do Norte-CE. Foram utilizados os procedimentos analíticos da pesquisa bibliográfica e de entrevista semiestruturada, caracterizando-se, portanto, de estudo qualitativo e descritivo. Os resultados da pesquisa apontam que participar dessa associação contribui para a divulgação dos trabalhos de seus associados, embora ainda persistam sérias dificuldades, tais como: a falta de capital de giro para a compra de matéria-prima e de uma sede própria para a comercialização dos produtos. O apoio da prefeitura municipal, neste sentido, é inexistente. A presidência da associação não buscou cursos de capacitação junto ao SENAC e ao Departamento de Economia da Universidade Regional do Cariri para gerenciar melhor os negócios dos associados, de modo a minimizar essa dificuldade.
\end{abstract}

Palavras-chave: Artesanato. Emprego. Renda. FEART.

Recebido em: 13/03/2016 I Aceito em: 29/07/2016

\footnotetext{
1 Bacharela em Ciências Econômicas pela URCA. E-mail: ana_mps09@hotmail.com

2 Mestra em Desenvolvimento Regional Sustentável pela UFC-Cariri. Professora do curso da Administração Pública da UFCA. E-mail: romeniasol@bol.com.br
}

Ciência e Sustentabilidade - CeS | Juazeiro do Norte v. 2, n. 1, p. 124-148, jan/jun 2016 I ISSN 2447-4606 


\section{INTRODUÇÃO}

O artesanato brasileiro é um dos mais ricos e diversificados do mundo, possuindo amplas perspectivas de expansão no mercado internacional. Cada região apresenta um estilo típico, feito de acordo com as matérias-primas que cada uma oferece e o costume do seu povo. As peças artesanais guardam tradições que vão ganhando novos traços com o passar do tempo. Contudo, não perde sua originalidade, fruto da herança de raças distintas. Incentivar este setor econômico significa atenuar desigualdades sociais verificadas nas distintas regiões e preservar os valores culturais locais. Dados do SEBRAE (apud CARMO, 2011) indicaram uma movimentação de cerca de $R \$ 28$ bilhões ou 2,8\% do Produto Interno Bruto (PIB) do país, aproximando-se da contribuição da indústria automobilística (3\% do PIB).

O artesanato no Ceará provém da inegável herança cultural legada pelos povos portugueses, indígenas e negros. Já o artesanato de Juazeiro do Norte está relacionado ao contexto histórico do seu surgimento e ao crescimento econômico vivido pela cidade em meados de 1890. Possui um forte impacto na construção da identidade cultural local. Por sua beleza e pela qualidade dos artefatos, atrai muitos visitantes que sempre encontram algo agradável, e consequentemente são "tentados" a adquirir algum objeto. Mas, o setor perdeu sua centralidade econômica, tornando-se, nos anos 2000, uma atividade marginal no município, sem sequer aparecer no cálculo do PIB municipal por sua baixa participação e informalidade. Além das dificuldades e apoio escasso por parte dos órgãos públicos locais.

Diante do exposto, este artigo tem como objetivo principal mostrar de que forma a Associação dos Artesãos da Feira de Artesanato (FEART) contribui para o fortalecimento e desenvolvimento do setor artesanal em Juazeiro do Norte-CE através deu um estudo realizado em 2014 com os membros associados. Trata-se de uma pesquisa com abordagem qualitativa e metodologia descritiva. Para tal, foram utilizados os procedimentos de pesquisa bibliográfica e de entrevista, conforme descritos na sequência. 
Não raro a pesquisa bibliográfica é confundida com revisão de literatura, sendo que a primeira implica um conjunto ordenado de procedimentos de busca por soluções, atentando para o assunto estudado, e contribuindo com elementos que subsidiem a análise futura dos dados. Portanto, vai além da simples observação de dados, imprimindo sobre estes a teoria, a compreensão e a crítica aos significados existentes. Sua escolha se deu pela possibilidade de acesso à ampla gama de informações dispersas em várias publicações, auxiliando a construção de um panorama conceitual para objeto de pesquisa. Exige do pesquisador o cumprimento de procedimentos que compreendem quatro fases contínuas: a elaboração do projeto de pesquisa; a investigação das soluções; a análise explicativa destas; e a síntese integradora. Após a coleta de dados, escolhe-se a técnica para investigação, na qual a leitura permite reconhecer o material bibliográfico, explorá-lo, selecioná-lo, compreendê-lo e interpretá-lo. Fazse um roteiro para a leitura e, a seguir, uma síntese integradora (LIMA e MIOTO, 2007). Esta se constituiu a primeira etapa da pesquisa.

A entrevista, por sua vez, caracteriza-se como técnica qualitativa de apreensão da percepção e da vivência pessoal das situações e eventos do mundo. A relação entre entrevistador e entrevistado permite acessar os significados atribuídos pelas pessoas aos eventos, cujos resultados são frutos das mútuas influências interativas na entrevista. Foi utilizada a modalidade face a face e optou-se pelo tipo semiestruturado (ver anexos). Esta abordagem almeja compreender uma realidade particular, ao mesmo tempo em que permite a autorreflexão dos entrevistados e, talvez, até a ação emancipatória (FRASER e GONDIM, 2004). Este foi o segundo momento da pesquisa, realizado com os associados da FEART em 2014. A apresentação do estudo está dividida em três partes, além desta introdução e das considerações finais. A seção 1 caracteriza o setor artesanal em geral. A seção 2 mostra o comportamento do artesanato no Brasil, e as principais tipologias produzidas. Já a seção 3 apresenta o estudo sobre a FEART, mostrando seu desempenho e sua contribuição para a economia de Juazeiro do Norte. 


\section{ARTESANATO E DESENVOLVIMENTO LOCAL: CONCEITOS E CARACTERÍSTICAS}

O artesanato tanto pode ser analisado nas dimensões histórica, econômica e social quanto nas dimensões cultural e ambiental. A profissionalização da produção nesse setor vem se mostrando uma ferramenta de grande eficiência para a melhoria na qualidade de vida de diversas famílias.

[...] por muitos era visto como atividade econômica marginal, hoje é
tratada como atividade regular inserida no mercado competitivo. Em
países desenvolvidos as atividades artesanais geram, normalmente,
produtos de qualidade superior e de alto valor agregado, contribuindo
fortemente para o crescimento econômico e para o bem-estar social de
inúmeras pessoas. A Finlândia e Dinamarca são exemplos de países que
mantém essa relação próxima com o artesanato e onde essa atividade é
altamente sofisticada, destacando-se pela inovação e design criativo,
arrojado e moderno. (LEMOS, 2011, p.32).

Observa-se que além de proporcionar aos artesãos melhores condições de vida, esta atividade atua contra o desemprego. Nesse caso o artesanato pode ser considerado como um elemento de equilíbrio no país, onde se afirma como um componente essencial do crescimento das regiões e torna-se conhecido por suas potencialidades. A atividade artesanal está ligada a riqueza cultural bem como a uma forte vinculação com o setor turístico.

O artesanato interfere no tecido econômico e social, como fonte de rendimento e de emprego, além de ser um fator de ligação das populações com o seu território. Portanto o artesanato ocupa um lugar de destaque no âmbito das atividades econômicas, sendo um dos poucos setores, que ao longo dos anos tem combinado de forma singular um potencial econômico e de criação de emprego que são reconhecidos com uma vertente cultural e turística sempre presente (CEART, 2007 apud OLIVEIRA, 2009, p.39).

Apresenta-se como uma das formas mais ricas de expressão da cultura de um povo e do seu potencial criativo. Nos últimos tempos agrega-se a esse caráter cultural o viés econômico, com impacto na inclusão social e geração de trabalho e renda. $\mathrm{O}$ artesanato mostra-se como uma alternativa sustentável e até mesmo estratégica no crescimento econômico de certas localidades. Possui um forte impacto na construção de uma identidade local, contribuindo também para a caracterização da identidade cultural local. 


\subsection{Alguns conceitos sobre Desenvolvimento}

A ideia corrente de desenvolvimento refere-se a um processo de transformação econômica, política e social que engloba o conjunto de uma sociedade. $O$ desenvolvimento de qualquer sociedade constitui um processo complexo. Pensar em desenvolvimento leva positivamente a uma ideia de construção, de evolução. Ideia que busca sempre uma melhor opção a ser alcançada. O desenvolvimento econômico local está associado a um processo endógeno registrado em unidades territoriais. Está condicionado à capacidade da própria sociedade local conduzir o seu desenvolvimento. O desenvolvimento local endógeno, leva em consideração as especificidades de cada região bem como suas necessidades e suas potencialidades. O mesmo se dá com a participação efetiva dos atores sociais, ou seja, uma construção coletiva prevalecendo às necessidades de cada região sem modelos predeterminados (SANTOS, 2007).

Quando se menciona o desenvolvimento sustentável, emergem diversas definições. Mas o conceito ao qual será utilizado aqui trata de um processo de mudança na exploração dos recursos, na orientação dos investimentos e de desenvolvimento tecnológico e na mudança institucional todos em harmonia e melhorando o potencial existente e futuros. O conceito de sustentabilidade comporta as seguintes dimensões: social, econômica, ecológica, cultural, espacial, política e ambiental. Segundo Bursztyn (2001) a ética da sustentabilidade é a solidariedade com as gerações futuras, sem ela a sustentabilidade não existe, ela é apoiada num tripé onde precisam estar em perfeito equilíbrio com a economia, o social e o ambiental. Preservar o meio ambiente para que as gerações futuras tenham o que temos hoje.

Cabe destacar o conceito de sustentabilidade cultural. A cultura determina em grande proporção os processos de desenvolvimento. A cultura é uma síntese definida historicamente pela tradição dos componentes de determinado espaço geográfico. Abrange a construção de valores, costumes, princípios compartilhados, as visões de mundo, crenças, simbologias e formas de vida que se fazem comuns em dado espaço para a população. A cultura em si é que une 
um grupo social. O setor cultural por movimentar recursos de grande magnitude, tem a capacidade significativa de geração de empregos e rendas.

\subsection{Características, classificação e tipologias do Artesanato}

Segundo a Comissão Consultiva do Artesanato (apud LIMA e AZEVEDO, 1982) a atividade artesanal pode ser caracterizada de acordo com a matériaprima, o processo de produção, bem como as condições de trabalho. Quanto à matéria-prima utilizada na produção, a mesma pode ser natural, semielaborada, elaborada ou construída de sobras de produtos. Para cada matéria-prima principal derivam práticas profissionais que resultam em diversas tipologias de produtos bastante específicos. As principais matérias-primas são barro; fios e tecidos; metais; pedras; vidros; entre outros. O processo de produção deve ser predominantemente manual, podendo ser utilizadas ferramentas ou máquinas que não dispensem a criatividade e/ou habilidade pessoal na elaboração do produto ou execução do serviço. Pode ainda ser padronizada e as peças, mesmo sendo cópias, conservam sua individualidade em consequência de o trabalho ser predominantemente manual.

O artesão deve participar diretamente de todas ou quase todas as etapas e da elaboração do produto. A montagem individualizada de diversos componentes, mesmo anteriormente elaborados, porém feita sob os critérios referidos, resulta em artesanato. Toda atividade artesanal, para efeito de enquadramento nos benefícios do Programa Nacional de Desenvolvimento do Artesanato (PNDA), em sua fase inicial, deve resultar em produto, podendo o Ministério do Trabalho, oportunamente e por proposta da Comissão Consultiva, incluir no programa outras formas de atividade artesanal. (LIMA e AZEVEDO, 1982). Quanto às condições de trabalho, a atividade artesanal deve desenvolver-se em ambiente doméstico, pequenas oficinas, postos de trabalho ou centros associativos de produção. Mesmo aquelas realizadas de forma associativa nos termos da presente norma, exclui o vínculo empregatício.

A classificação do produto está definida conforme a origem, natureza da criação e de produção do artesanato. Essa classificação também determina os 
valores históricos e culturais do artesanato, no tempo e no espaço onde é produzido. De acordo com o Termo de Referência do Artesanato desenvolvido pelo SEBRAE (2010), se divide em: arte popular; trabalhos manuais; indígena; tradicional; de referência cultural; conceitual; produtos semi-industriais e industriais "industrianato/souvenir"; e produtos alimentícios típicos. E podem ser qualificados em adornos e/ou acessórios, decorativo, educativo, lúdico, religioso/místico, utilitário, profano e lembranças/souvenir.

Para o SEBRAE (2010) os produtores de artesanato, são também classificados de acordo com suas funções. Dentre elas destacam-se: Mestre artesão, Artesão, Aprendiz e Artista. Percebe-se que os produtores artesanais seguem uma hierarquia, sendo o mestre artesão o responsável para repassar todo seu conhecimento e técnicas; o artesão exerce a atividade propriamente dita, onde em alguns casos tem o auxílio dos aprendizes que participam de algumas fases de elaborações da produção. E segue o artista, que está em busca constante de algo novo. De acordo com o PAB (2012), o trabalho artesanal também compreende diversas formas de organização, tais como em núcleo de artesãos de produção familiar, grupo de produção artesanal, e núcleos mistos (associação, cooperativa, sindicato, federação e confederação).

\section{O ARTESANATO BRASILEIRO E SUAS CONTRIBUIÇÕES ECONÔMICAS}

A atividade artesanal brasileira assume uma elevada parcela de atividade econômica, fato que contribui para o desenvolvimento das demais regiões. De acordo com Figueiredo e Rodrigues Neto (2010), esta atividade tem forte tendência à expansão como atividade de produção em todo país, inclusive como fonte de emprego e renda. Segundo Santos (2007), o artesanato brasileiro é um dos mais ricos e diversificados do mundo, o mesmo possui amplas perspectivas de expansão no mercado internacional. Cada região brasileira apresenta um artesanato típico, feito de acordo com as matérias-primas que cada uma oferece e o costume do seu povo. As peças artesanais guardam tradições que vão 
ganhando novos traços com o passar do tempo, contudo, não perde sua originalidade, fruto da herança de raças distintas.

Na região Norte, predomina o artesanato com frutas e sementes, haja vista a abundância de matéria-prima existente. A influência indígena predomina tanto na culinária, como no artesanato utilizado para enfeites, e também faz da cerâmica uma das produções mais presentes. Na região Centro-Oeste, o foco está na produção do bordado. Nas regiões Nordeste e Sul há uma cultura múltipla e diversificada; destacam-se o bordado, o artesanato em barro e madeira. Devido às condições naturais dessas regiões, as mesmas possuem matéria-prima abundante. As maiores influências na região Sul é do povo europeu. A renda tem um papel importante nas regiões Norte, Nordeste e Sul, em especial a renda de bilros, trazidas pelos portugueses e colonos açorianos. No Sudeste o bordado é um dos tipos de artesanato mais produzido. A culinária típica nessa região é bem diversificada, apresentando influência dos índios, escravos e dos diversos imigrantes europeus e asiáticos.

$\mathrm{Na}$ tabela 01 verificam-se os tipos de artesanato mais produzidos no Brasil, no ano de 2009, bem como apresenta o valor percentual de cada uma.

\begin{tabular}{lrr}
$\begin{array}{l}\text { Tabela 01 } \text { - atividades artesanais mais produzidas no Brasil em 2009 } \\
\text { Atividade } \\
\text { artesanal }\end{array}$ & $\begin{array}{c}\text { Quantidade } \\
\text { produzida }\end{array}$ & $\begin{array}{c}\text { Percentual } \\
\text { produzido }\end{array}$ \\
\hline Bordado & 4.081 & $28,30 \%$ \\
\hline Madeira & 1.900 & $13,20 \%$ \\
\hline Culinária típica & 1.419 & $9,80 \%$ \\
\hline Barro & 1.142 & $7,90 \%$ \\
\hline Material reciclável & 954 & $6,60 \%$ \\
\hline Fibras vegetais & 811 & $5,60 \%$ \\
\hline Tapeçaria & 679 & $4,70 \%$ \\
\hline Couro & 596 & $4,10 \%$ \\
\hline Fios e fibras & 563 & $3,90 \%$ \\
\hline Frutas e sementes & 496 & $3,40 \%$ \\
\hline Outros & 437 & $3 \%$ \\
\hline Renda & 374 & $2,60 \%$ \\
\hline Tecelagem & 370 & $2,60 \%$ \\
\hline
\end{tabular}

Ciência e Sustentabilidade - CeS | Juazeiro do Norte v. 2, n. 1, p. 124-148, jan/jun 2016 


\begin{tabular}{lrr}
\hline Pedras & 178 & $1,20 \%$ \\
\hline Conchas & 173 & $1,20 \%$ \\
\hline Vidro & 105 & $0,70 \%$ \\
\hline Metal & 84 & $0,60 \%$ \\
\hline Pedras preciosas & 46 & $0,30 \%$ \\
\hline TOTAL & $\mathbf{1 4 . 4 0 8}$ & $\mathbf{1 0 0 \%}$ \\
\hline
\end{tabular}

Fonte: Elaboração Própria. Dados MUNIC/IBGE, 2009.

O bordado é a atividade mais produzida em todo o país, representando $28,30 \%$ da produção total. A madeira vem em segundo lugar com $13,20 \%$ do total produzido, segue-se a culinária típica com 9,80\% e em quarto lugar, o artesanato em barro, com $7,90 \%$ do total da produção. Na tabela 02 , podemos observar a quantidade de artesanato produzida em geral, por cada estado brasileiro, dos maiores para os menores produtores. Mesmo sendo mínima, em alguns estados, a participação do artesanato, há presença dessa atividade em todos eles.

Tabela 02 - Quantidade de atividades artesanais mais produzidas por estado no em 2009

\begin{tabular}{lrr}
\hline \multicolumn{1}{c}{ Estados } & Quantidade Produzida & Participação \% \\
\hline Minas Gerais & 2.286 & 15,87 \\
\hline São Paulo & 1.541 & 10,70 \\
\hline Rio Grande Do Sul & 1.302 & 9,04 \\
\hline Bahia & 1.156 & 8,02 \\
\hline Paraná & 971 & 6,71 \\
\hline Santa Catarina & 806 & 5,59 \\
\hline Goias & 635 & 4,42 \\
\hline Paraíba & 573 & 3,98 \\
\hline Ceará & 522 & 3,62 \\
\hline Maranhão & 506 & 3,52 \\
\hline Piauí & 503 & 3,49 \\
\hline Pernambuco & 501 & 3,48 \\
\hline Rio Grande Do Norte & 453 & 3,14 \\
\hline Pará & 392 & 2,72 \\
\hline Mato Grosso & 358 & 2,48 \\
\hline Alagoas & 279 & 1,94 \\
\hline Tocantins & 275 & 1,91 \\
\hline Rio De Janeiro & 264 & 1,83 \\
\hline Espirito Santo & 224 & 1,55 \\
\hline Mato Grosso Do Sul & 220 & 1,52 \\
\hline Sergipe & 200 & 1,39 \\
\hline Amazonas & 174 & 1,22 \\
\hline Rondônia & 120 & 0,83 \\
\hline
\end{tabular}

Ciência e Sustentabilidade - CeS | Juazeiro do Norte v. 2, n. 1, p. 124-148, jan/jun 2016 


\begin{tabular}{lrrr}
\hline Acre & 61 & 0,42 \\
\hline Amapá & 45 & 0,32 \\
\cline { 1 - 2 } Roraima & 38 & 0,26 \\
\hline Distrito Federal & 3 & 0,03 \\
\hline \multicolumn{1}{l}{ Total } & $\mathbf{1 4 . 4 0 8}$ & $\mathbf{1 0 0 , 0}$ \\
\hline
\end{tabular}

Fonte: Elaboração Própria. Dados MUNIC/IBGE, 2009.

Minas Gerais é apresenta o maior número de artesanato produzido, com $15,9 \%$ do total das atividades. A intensa industrialização de São Paulo faz com que a produção do artesanato se torne menos evidente, apesar de ser rico e marcado pela influência dos colonizadores e imigrantes e pela tradição cultural caipira, caiçara e indígena, principalmente dos tupis e guaranis. O Rio Grande do Sul, terceiro maior produtor, tem no couro bovino sua principal matéria-prima. A Bahia encanta por seu artesanato enraizado na herança cultural dos africanos, índios e portugueses. Já o Distrito Federal, menor produtor de artesanato, tem fontes de inspirações na abundância de matérias-primas existentes no cerrado. É nesse cenário árido que podem ser encontrado sementes, folhas e flores de aparência rústicas, e bonitas. (BRASIL, 2002).

O gráfico 01 apresenta o percentual de produção artesanal por região brasileira em 2009. A região Nordeste é a que mais se destaca na produtividade artesanal no Brasil, representando $33 \%$ do total de artesanato produzido no país. Isso se dá pelo seu grande potencial turístico, que vem crescendo aceleradamente, tornando mais viável o desenvolvimento e articulação do artesanato regional, que vem a ser uma fonte de encantamento para os visitantes.

\title{
Gráfico 01 - Distribuição \% da produção artesanal por
} regiões brasileiras em 2009.

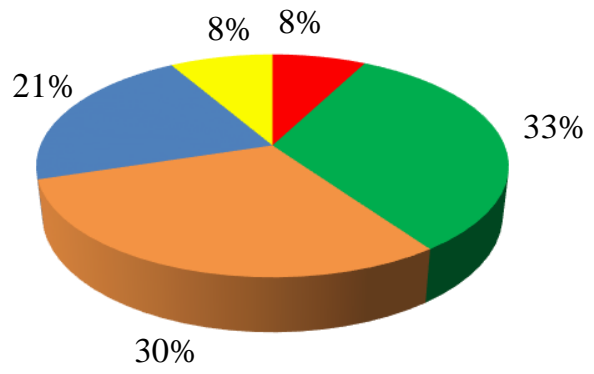

\author{
- NORTE \\ - NORDESTE \\ $\square$ SUDESTE \\ $\square$ SUL \\ CENTRO OESTE
}

Fonte: Elaboração Própria. Dados MUNIC/IBGE, 2009. 
De acordo com o Ministério de Desenvolvimento, a atividade artesanal tem exercido no Brasil um papel preponderante na ocupação e geração de renda para mais de 8,5 milhões de pessoas. Por sua vez um estudo elaborado pelo Banco do Nordeste, mostra a existência de aproximadamente 3,3 milhões de pessoas inseridas na atividade na região nordeste.

O quantitativo de artesãos no Nordeste brasileiro constitui um contingente significativo de trabalhadores do mercado informal. Os artesãos encontram na produção de artesanato uma forma de garantir sua própria subsistência e de suas famílias. Nessa perspectiva, estimular o desenvolvimento do artesanato nordestino significa abrir possibilidades de atenuação das desigualdades sociais verificadas na região, além de promover a preservação de valores da cultura local (BNB, 2002, p.07).

Entre as vocações em cadeias produtivas, o artesanato tem um elevado potencial de ocupação e geração de renda. O mesmo registra a ocorrência em mais de 600 municípios, da região nordeste, produzindo 11 tipologias e 57 segmentações que contemplam diversos produtos, como mobiliários, tapetes, imagens sacras, esculturas, instrumentos musicais, brinquedos, jarros, acessórios de vestuário, doces e bebidas regionais, utilidades para o lar, artigos de cama, mesa e banho; todos eles testemunhos do talento inato de uma gente que usa as mãos para transformar em arte todo o seu infinito potencial criativo (BNB, 2002).

De acordo com o SEBRAE (apud CARMO, 2011), movimenta cerca de R $\$$ 28 bilhões ou 2,8\% do Produto Interno Bruto (PIB) do país, superando indústrias tradicionais como bebidas (1\%) e vestuário $(2,7 \%)$, aproximando-se de uma das mais tradicionais indústrias brasileiras, a automobilística, responsável por pouco mais de $3 \%$ do PIB. Estima-se que o rendimento médio mensal seja de (três) salários mínimos, gerando uma renda anual de $R \$ 30$ bilhões (SANTOS, 2007).

Segundo Pereira (1979, apud SOUSA, 2010), o artesanato no Ceará provém da inegável herança cultural legada por três raças distintas, formadoras do povo cearense: portugueses, índios e negros. Desse modo, os indígenas que os colonizadores encontraram já eram artesãos do tecido e da cerâmica sedimentar, deles vieram também as vertentes dos trabalhos em barro, corda e palha, cuja difusão se deu em função do utilitarismo. Já dos europeus, herdou-se principalmente a renda e o labirinto. Os africanos contribuíram com a cerâmica 
cozida cuja beleza rústica, resistência e ampla funcionalidade disseminaram e mantiveram seu uso até o presente.

O artesanato produzido no Ceará utiliza-se de matérias-primas como: a madeira, o barro ou argila, couro, ouro, palha, areia, algodão e corda, dando origem assim a uma grande diversidade de produtos, como por exemplo, a renda, cerâmica, bordados labirintos, garrafinha de areia colorida, móveis, artes sacras, objetos de decoração, dentre outros. A Central do Artesanato (CEART) já catalogou mais de 10.000 itens, classificando-os em 26 tipos diferentes de produtos comercializados. Atualmente mesmo com a diversidade de produtos tecnológicos e modernos, essa quantidade de opções caracteriza uma necessidade de consumo por produtos que simbolizem o apego às culturas tradicionais, simples e mais distantes dos processos mecanizados (LÓCIO et al, 2006 apud OLIVEIRA 2009, p.43).

\section{HISTÓRIA DO ARTESANATO EM JUAZEIRO DO NORTE - CEARÁ}

A produção do artesanato municipal está relacionada ao contexto histórico do seu surgimento e ao crescimento econômico, vivido pela cidade, em meados de 1890 (VALE, 2012). A figura do padre Cícero é reconhecida na história, na literatura e principalmente na memória dos artesãos, como um grande incentivador da atividade artesanal a partir de sua concepção de trabalho e fé (ARAUJO, 2005). A ação evangelizadora que unia trabalho e fé foi importante para o desenvolvimento da região e de Juazeiro, tanto em termos religiosos como também políticos, sociais e econômicos. Devido às estiagens pelas quais passava à região, a população não poderia depender unicamente da atividade rural. Outro fato também que levou os habitantes do lugarejo a buscar outra atividade econômica que garantisse sua subsistência, era a distância entre Juazeiro e os principais centros urbanos. A partir de então começa a tomar forma o trabalho artesanal como atividade econômica de subsistência. (GRANGEIRO e SILVA JÚNIOR, 2013). 
São comuns os relatos de como o Padre Cícero, incentivava a produção artesanal e manufatureira, sobretudo entre a população mais pobre. Era uma forma de garantir trabalho e renda para as famílias em um local ainda sem indústrias e com uma produção agrícola prejudicada pelas longas estiagens e marcada pela exploração do agricultor. A memória do "Padim Ciço", como era chamado pelos seus fiéis seguidores, ainda marca fortemente a produção artesanal da região, seja pela evocação da sua própria imagem, esculpido em madeira, gesso, argila e retratado nos mais diversos materiais ou pela permanência de seus ensinamentos que valorizavam a fé e o trabalho (VALE, 2012, p.14).

"A elevada produção artesanal do período fez com que a cidade fosse chamada, na época, de Cidade-Oficina" (GRANGEIRO e SILVA JÚNIOR, 2013, p.29).

Os artesãos do Padre Cícero se organizavam a partir da economia informal, com produção em pequena escala por unidade de produção, utilizando, predominantemente a mão-de-obra temporária. A economia apresentava, portanto, grande mobilidade de capital humano, construindo, assim, uma complexa organização econômica para assegurar as condições de subsistência e reprodução simplificada da força-de-trabalho (ARAUJO, 2005, p. 93).

Nas décadas seguintes o setor artesanal foi perdendo sua centralidade econômica, tornando-se, nos anos 2000, uma atividade marginal na vida econômica de Juazeiro do Norte, de modo que não aparece no cálculo do PIB Municipal por sua baixa participação. Alguns fatores entre as décadas de 1970 a 2000 começaram a minimizar a atividade artesanal na cidade.

A industrialização de produtos próprios do local e a modificação dos traços culturais reduzem o consumo de artigos como louças de barro, selaria e trançado. A diminuição do consumo de panelas de barro por panelas de alumínio, bem como o uso de calçados de couro por calçados de borracha. (GRANGEIRO e SILVA JÚNIOR, 2013, p.32)

Nesse contexto em que há um enfraquecimento da atividade artesanal, várias são as dificuldades enfrentadas pelos artesãos na realização do seu trabalho. Apesar desse enfraquecimento pelo qual passou a atividade artesanal na região ao longo do tempo, a cidade de Juazeiro do Norte continua sendo o maior polo de artesanato cearense, possuindo forte representatividade para a cultura popular tanto do estado do Ceará quanto do Brasil. O artesanato tem grande representatividade na cidade de Juazeiro do Norte. A mesma conta com várias associações que produzem diversas tipologias de produtos artesanais. Pode-se

Ciência e Sustentabilidade - CeS | Juazeiro do Norte v. 2, n. 1, p. 124-148, jan/jun 2016 
destacar, dentre elas: Grupo de Produção Família Cândido; Associação dos Artesãos Mãe das Dores e do Padre Cícero; Grupo de Artesanato em Palha de Milho; Associação Lira Nordestina e Associação dos Xilógrafos; Centro de Cultura Mestre Noza (OLIVEIRA, 2009); Associação Lapidários e Ourives do Cariri; e a Associação dos artesãos da FEART (GRANGEIRO e SILVA JÚNIOR, 2013).

\subsection{Fundação da Associação FEART}

De acordo com pesquisa feita com os artesãos da FEART, a ideia de formar uma feira de artesanato se deu a partir de uma exposição de produtos artesanais no bairro do Novo Juazeiro, com os artesãos locais. Vendo que poderia dar certo, uma das artesãs procurou a prefeitura e buscou esse incentivo. Foi movimentando a ideia entre os artesãos, de exporem mais seus trabalhos. A primeira feira aconteceu em 2000, no estacionamento do Cariri Shopping, onde somavam aproximadamente 12 pessoas, que passaram consecutivamente a se reunirem em diversas praças da cidade, levando o encanto, criatividade e a beleza de suas artes para diversas pessoas. Nesse tempo contavam com apoio da prefeitura, principalmente no transporte, onde a mesma disponibilizava ônibus para a locomoção tanto dos artesãos, como dos artesanatos por eles produzidos. A partir de então, com o sucesso da feira, no dia 29 de novembro de 2004, formou-se uma equipe e foi criada a associação, cujo nome deu-se Associação FEART.

De acordo com entrevista feita com o presidente e vice-presidente da Associação, o propósito maior da mesma é de divulgar o trabalho e facilitar a venda dos produtos dos artesãos associados. A associação mantém-se somente com a ajuda dos associados, com uma taxa de $\mathrm{R} \$ 10,00$ por mês. Mas nem sempre esse valor é o suficiente para suprir as necessidades da Associação, que muitas vezes terminam em prejuízos. Hoje a Associação é composta por 28 associados. Os dados apresentados a seguir foram tabulados com 25 dos associados, pois três deles, não estavam frequentando a feira, e não se dispuseram a responder a entrevista proposta. A pesquisa aconteceu entre agosto e setembro de 2013. 


\subsection{Aspectos sociais dos artesãos da FEART}

Dos 25 respondentes, três eram homens e 22 mulheres. O número de mulheres destaca-se na produção artesanal. De acordo com Grangeiro e Silva Júnior (2013), talvez a necessidade da mulher complementar sua renda ou a mesma tornar-se o seu principal meio de subsistência, obrigou a mesma a buscar uma atividade econômica, e o artesanato seria uma opção mais viável para que a mulher pudesse trabalhar em sua própria casa. $\mathrm{Na}$ tabela 03 pode-se observar a faixa etária dos artesãos entrevistados.

\begin{tabular}{l|r|r}
\multicolumn{3}{c}{ Tabela 03 - faixa etária } \\
\hline \multicolumn{1}{c}{ Idade } & $\begin{array}{c}\text { Frequênci } \\
\text { a }\end{array}$ & Percentual \\
\hline 25 a 35 anos & 7 & $28 \%$ \\
36 a 45 anos & 9 & $36 \%$ \\
46 a 60 anos & 8 & $32 \%$ \\
Mais de 60 & 1 & $4 \%$ \\
\hline Total & 25 & $100 \%$ \\
\hline
\end{tabular}

Fonte: Pesquisa Direta. (2013).

A maioria dos artesãos tem entre 36 e 45 anos. $O$ artesanato parece ser um ofício pouco atrativo para os mais jovens que não veem nessa atividade uma fonte de renda suficiente para suprir as necessidades econômicas e nem uma atividade valorizada socialmente. (GRANGEIRO e SILVA JÚNIOR, 2013). "Em um mercado de trabalho cada vez mais restrito e exigente, o artesanato tem sido uma opção estratégica para reduzir a pressão social causada pela baixa capacidade de absorção da larga faixa da mão-de-obra disponível na sociedade". (OLIVEIRA, 2009, p.59). Quanto ao grau escolaridade, pode-se observar no gráfico 02. 


\section{Gráfico 02 - escolaridade}

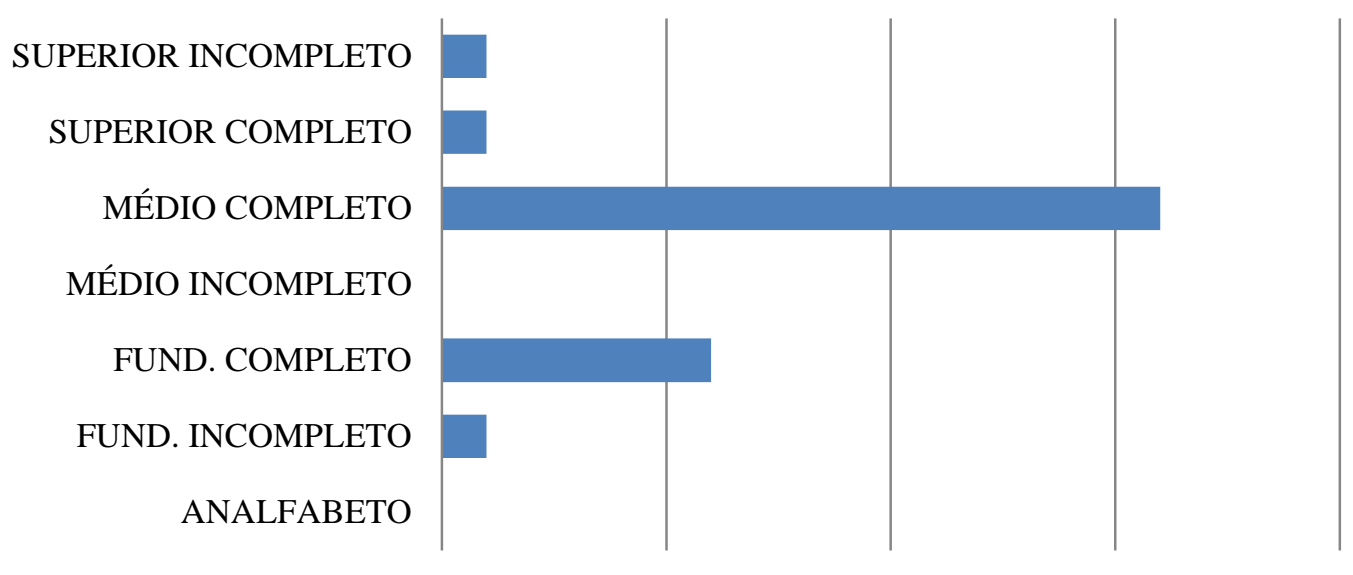

Fonte: Pesquisa direta (2013).

Observa-se que não há nenhum grau de analfabetismo, e somente um dos artesãos entrevistados tem ensino fundamental incompleto. O percentual de artesãos que concluíram o ensino médio é bastante expressivo, 16 dos entrevistados afirmaram ter o ensino médio completo. Importante salientar também que entre os entrevistados um tem ensino superior completo, e um tem o ensino superior incompleto. Nesse caso uma das artesãs é formada em Administração, e outra concluindo o curso de Pedagogia; ambas apesar da escolaridade encontram na atividade artesanal uma fonte de renda que, de certa maneira tem suas contribuições.

\subsection{Aspectos produtivos do artesanato}

$\mathrm{Na}$ pesquisa feita com os artesãos, buscou-se observar os tipos de artesanato por eles produzidos, bem como o tempo de trabalho com o artesanato, e com quem aprenderam esse ofício. Ou seja, quais as suas principais motivações para desenvolver essa atividade. Observamos que na FEART há uma variedade

Ciência e Sustentabilidade - CeS | Juazeiro do Norte v. 2, n. 1, p. 124-148, jan/jun 2016 
de produtos artesanais, totalizando 14 tipos diferentes. No entanto predomina 0 artesanato em madeira com total de oito artesãos produzindo, seguido do artesanato em biscuit, produzidos por seis artesãos, e pintura em tecido e comidas com por cinco dos artesãos entrevistados. De acordo com Oliveira (2009) a madeira ao longo dos anos vem sendo a principal fonte de matéria-prima na produção de objetos que fazem parte do acervo da cultura material brasileira, a mesma é utilizada para fazer uma infinidade de produtos.

Quando questionado sobre o tempo de trabalho dos artesãos, 13 dos artesãos exercem essa função entre 01 a 10 anos. Sete dos artesãos exercem esse ofício a mais de 10 anos. E um artesão estava com mais de 30 anos de trabalho. A maioria dos entrevistados possui estabilidade na atividade artesanal, onde tiram o seu sustento e de onde sai sua principal renda. Quando perguntados sobre a importância do artesanato e o que essa atividade traz de beneficio, os 25 artesãos entrevistados responderam ser essa atividade de suma importância, pois além de beneficiar financeiramente, ser uma fonte de renda, para muitos o único meio de subsistência; produzir o artesanato serve como terapia ocupacional, além de ser uma atividade prazerosa e de estimulo à criatividade. Importante salientar que para muitos trabalhar com o artesanato é preciso ter amor pelo mesmo, é preciso ter amor pelo o que faz, porque é uma maneira de expressar na arte aquilo que está em seu interior.

Em relação ao aprendizado do oficio artesanal, nove dos artesãos aprenderam a fazer o artesanato através de familiares e nove, sozinhos. Sete dos entrevistados responderam ter aprendido através de cursos. Ainda de acordo com a pesquisa alguns aprenderam a atividade artesanal pela necessidade e até mesmo pela curiosidade. No entanto, permanecem na atividade por se identificarem com a mesma e pelos benefícios financeiros adquiridos.

\subsection{Aspectos econômicos dos artesãos da FEART}

Quando perguntado se o artesanato era a única fonte de renda, para 10 dos artesãos a resposta foi afirmativa, já para 15 dos entrevistados é apenas um 
complemento da renda. Como a maioria dos artesãos da FEART é composta por mulheres, é correto afirmar que a renda familiar obtida não é necessariamente do artesanato, pois a maioria das artesãs conta com a renda do esposo, recebem outros tipos de benefícios, ou exercem atividades além da artesanal. Questionados sobre a renda mensal através do artesanato, 13 artesãos afirmaram obter menos de um salário mínimo por mês, seis dentre eles afirmaram receber cerca de um salário mínimo e seis artesãos obtêm mais de um salário mínimo por mês. É importante salientar, que essa quantia em dinheiro, não corresponde somente ao total vendido nas feiras. Segundo os artesãos, os mesmos vendem em suas próprias casas também, por não haver um espaço diário para expor seus produtos. Às vezes, mesmo que difícil, cerca de três artesãos, afirmaram que chegam a obter, até mais de dois salários mínimos por mês, com a venda dos produtos.

\subsection{Produção e Mercado - contribuições da FEART para o setor de artesanato de Juazeiro do Norte-CE}

Quando perguntados para quem vendem os produtos, a pesquisa buscou identificar de onde provêm os principais compradores do artesanato. Os principais consumidores são originários de diversas regiões do Brasil. Os dados indicados por nove artesãos revelaram que sua arte é consumida especialmente por turistas, seis deles afirmaram que vendem mais para os romeiros, cinco artesãos afirmaram que seus produtos são adquiridos por consumidores de Juazeiro do Norte. E cinco artesãos afirmaram que a maioria das vendas é por encomenda, tanto de consumidores locais quanto turistas. De acordo com alguns entrevistados os turistas são os que dão mais valor ao artesanato, independente do valor monetário da peça, de certa forma, o trabalho artesanal torna-se mais atrativo.

Quando questionados se havia alguma vantagem em fazer parte da associação, dez pessoas afirmam que as principais vantagens estão na divulgação do trabalho; seis citaram o retorno financeiro. Porém outras vantagens podem ser destacadas: as amizades construídas. Apesar de muitas vezes o 
retorno financeiro não ser tão bom como esperado, 10 artesãos mencionaram que, o fato de poderem expor seus produtos, é uma maneira das pessoas reconhecerem seus trabalhos, mesmo que não haja vendas no momento, muitas pessoas veem, e sentem-se atraídas, para em outra oportunidade adquiri-los.

Das principais dificuldades apontadas pelos artesãos da FEART para a produção do artesanato, a que teve maior índice foi falta de capital de giro para a aquisição da matéria prima, mencionada por 11 artesãos. Dois artesãos apontaram o fato da produção ser lenta. Como o trabalho exige muito tempo para o término do produto final, muitos deixam de vender ainda mais, por não haver tempo suficiente para produzir. E pelo processo ser um pouco demorado. Para as mães de família se torna até mais difícil, porque tem que dividir o trabalho artesanal com os trabalhos domésticos. Para cinco dos entrevistados, eles não encontram dificuldades em produzir o seu trabalho, tendo maiores vantagens, como por exemplo, o tempo suficiente para produzir, sem que exerçam outra atividade, e fácil acesso à matéria-prima, utilizada no processo da produção.

Também foram questionados sobre as principais dificuldades para a comercialização: oito afirmaram ser a falta de uma sede própria, especificamente para a venda dos produtos, e a fabricação dos mesmos. Cinco deles afirmam não haver freguesia suficiente para a oferta, e muitas vezes são prejudicados, como é o caso dos que trabalham com comidas e bebidas. Durante a entrevista foi perguntado o que deveria mudar na associação para que as coisas ficassem melhores. Para alguns estava tudo bom, nada deveria mudar. Para outros, gostariam que a associação tivesse mais apoio, por parte da prefeitura, principalmente na questão do transporte, pois muitas vezes os artesãos são prejudicados por terem que pagar fretes, cujo valor, chega a ser superior a venda do dia.

Eles gostariam, também, que a prefeitura firmasse a feira somente na praça padre Cícero, mais centralizada e de maior acesso, assim as vendas seriam melhores, especialmente no tempo das romarias. Alguns acreditam que se os artesãos fossem mais empenhados e unidos seria bem melhor para adquirirem, por exemplo, uma maquineta apontada por um artesão entrevistado como 
necessária, pois, muitas vezes, ele deixa de vender seus produtos por não ter como o cliente utilizar o cartão de crédito.

É importante ressaltar que os artesãos entrevistados gostariam de ter um local fixo, uma sede própria, para que pudessem trabalhar todos os dias, sem que sejam em suas casas. $O$ fato de ter a sede própria facilitaria a produção, e até mesmo a venda dos produtos, sendo também um meio para divulgação dos mesmos. Pois mesmo quem queira comprar algum produto e, no entanto não há a possibilidade em determinado momento, aquela pessoa saberá onde se encontra os artesãos e será atraído ao mesmo local no intuito de levar a mercadoria que desejara.

\section{CONSIDERAÇÕES FINAIS}

O incentivo à produção artesanal constitui numa forma alternativa de estimular às economias de base local, garantindo a preservação da cultura bem como a geração de emprego e renda para inúmeras famílias, considerando que grande parte dessas pessoas encontra no artesanato garantias para a própria sobrevivência e o bem estar de seus familiares (LEMOS, 2011). Observou-se, para os artesãos da FEART, esta última constatação.

Participar da FEART é a maneira pela qual os artesãos, em grupo, divulgam seus trabalhos, e se apresenta como a maneira mais atrativa para seu possível público. O propósito maior da FEART, aliás, é divulgar o trabalho dos artesãos e facilitar a venda dos produtos, no entanto, não fazer parte da associação tornaria a vida deles mais difícil, pois encontrariam maiores dificuldades para a comercialização e divulgação dos seus trabalhos.

Durante as entrevistas ficaram claras as dificuldades relacionadas à falta de capital de giro para a compra de matéria-prima, a carência de uma sede própria para a comercialização dos produtos. Caberia à prefeitura municipal contribuir neste sentido, afinal Juazeiro do Norte é um município cuja economia é fortemente alavancada pelo setor de serviço, e tem nas romarias uma inquestionável fonte de rendas durante todo o ano. Como não poderia deixar de ser, a atividade artesanal 
também se encontra relacionada com aquela, e deveria ser vista como um dos produtos turísticos municipal.

Vale ainda uma observação sobre o problema da falta de capital de giro bastante mencionada pelos artesãos. Não foi o foco da pesquisa descobrir como os artesãos gerenciam esse capital, mas, por ser a maior dificuldade, caberia a presidência da associação buscar cursos de capacitação junto ao SENAC e ao Departamento de Economia da Universidade Regional do Cariri para gerenciar melhor os negócios dos associados buscando soluções minimizadoras dessa dificuldade.

\title{
THE ECONOMIC ASPECTS OF THE CRAFTS IN ASSOCIATION OF ARTISANS IN JUAZEIRO DO NORTE - CEARÁ, 'FEIRA DE ARTESANATO - FEART'
}

\begin{abstract}
The craft industry occupies a prominent place in the framework of economic activities. The artisanal activity presents itself as a source of employment and income for more than 8,5 million people in Brazil, and moves about to $R \$ 28$ billion, or 2.8 percent of gross domestic product of the country. The artisanal activity in addition to bring improvements in the living conditions of craftsmen contributes to the local economic development of each region. The craft is connected to the cultural wealth as well as a strong linkage with the tourist sector. This work will provide information about the topic: Economic Aspects of the craft of Juazeiro do Norte-CE: the case of the Association of artisans of FEART. The same aims to show how the main FEART contributes to the strengthening and development of the small-scale sector in Juazeiro do Norte-CE, and as specific goals: characterize the artisanal sector and its possible contribution to the process of local development; synthesize the behavior of the sector in Brazil and craft their economic contributions; and identify the contributions of FEART artisanal sector development in Juazeiro do Norte-CE. Analytical procedures were used in the bibliographical research and semi-structured interview, characterized, therefore, qualitative and descriptive study. The survey results indicate that participate in this Association contributes to the dissemination of the work of its members, though still serious difficulties persist, such as: the lack of working capital for the purchase of raw material and a place for the marketing of products. The support of the municipal government, in this sense, is non-existent. The Presidency of the Association did not seek training courses by the SENAC and the Department of Economics at the University of Cariri Regional to better manage the business of the Associates, in order to minimize this difficulty.
\end{abstract}

Keyword: Crafts. Employment. Income

Ciência e Sustentabilidade - CeS | Juazeiro do Norte v. 2, n. 1, p. 124-148, jan/jun 2016 


\section{REFERÊNCIAS}

ARAUJO, M. L. de. A cidade do Padre Cícero: trabalho e fé. Rio de Janeiro, 2005. 259p. Tese (Doutorado em Planejamento Urbano e Regional). Universidade Federal do Rio de Janeiro - UFRJ.

BNB. Banco do Nordeste do Brasil. Ações para o Desenvolvimento do Artesanato do Nordeste. 2002. Disponível em: <http://banconordeste.gov.br> Acesso em: 18/04/ 2012.

BARROSO, E. O que é artesanato. Curso de artesanato, primeiro módulo. 2000. Disponível em:< http:// www.Fbes.org.br/index. php?option=com_docman\&task> Acesso em 25/ 05/ 2012.

BRASIL. Ministério do Desenvolvimento. Programa do Artesanato Brasileiro. A arte do Artesanato Brasileiro. São Paulo/SP. Talento, 2002. 179 p.

BURSZTYN, M. Ciência, Ética e Sustentabilidade. São Paulo: Cortez; Brasília DF: UNESCO, 2001.

CARMO, P. S. de S. O Artesão Brasileiro. Intérprete da cultura regional e artífice da economia solidária. Dissertação (Mestrado). Pontifícia Universidade Católica de Minas Gerais. Belo Horizonte, 2011. Disponível em:< http://www.biblioteca.pucminas.br/teses/Direito_CarmoPSS_1.pdf.>Acesso em 15/04/2012.

FIGUEIREDO, C. M.; RODRIGUES NETO, M. O Engenheiro de Produção e a Produção Artesanal: Uma alternativa em busca pelo produto individual. In: $\mathbf{X X X}$ Encontro Nacional de Engenharia de Produção. São Carlos - SP. Outubro, 2010. Disponível em:

<http://www.abrepo.org.br/biblioteca/enegep2010_TN_STO_122_790_15372.pdf>. Acesso em 16/11/2011.

FRASER,M. T. D.; GONDIM, S. M. G. Da fala do outro ao texto negociado: discussões sobre a entrevista na pesquisa qualitativa. In: Paidéia, 2004, 14(28), p.139-152. 
GRANGEIRO, R. R.; SILVA JÚNIOR, J. T. Perfil dos Artesãos do Padre Cícero no século XXI. Juazeiro do Norte/CE. LIEGS, maio 2013.

LEMOS, M. E. S. O Artesanato como Alternativa de Trabalho e Renda. Subsídios para avaliação do Programa Estadual de Desenvolvimento do Artesanato no Município de Aquiraz - CE. Dissertação de Mestrado. Universidade Federal do Ceará - UFC. Fortaleza - CE, 2011.

LIMA, A. A. de M.; AZEVEDO, I. M. O Artesanato nordestino: características e problemática atual. Fortaleza, BNB. ETENE,1982.

LIMA, T. C.; MIOTO, R. C. T. Procedimentos metodológicos na construção do conhecimento científico: a pesquisa bibliográfica. In: Revista Katál. Florianópolis, v.10, n. esp. P.37-45, 2007.

OLIVEIRA, P. T. Arranjo produtivo local: O caso do artesanato em madeira na cidade de Juazeiro do Norte - CE. 2009. Monografia (graduação em Ciências Econômicas). Universidade Regional do Cariri - URCA.

PERICO, R. E. Identidade e Território no Brasil. Ministério do Desenvolvimento Agrário-MDA. Brasília, 2009.

Pesquisa Espacial da Atividade Artesanal. Pesquisa de Informações Básicas Municipais - MUNIC/2009 - IBGE. Brasília - DF. Fevereiro, 2012. Disponível em: http//www.mdic.gov.br/arquivos/dwnl_1338578535.pdf. Acesso em 16/04/2013.

Programa do Artesanato Brasileiro - PAB. Base Conceitual do Artesanato Brasileiro. Ministério do Desenvolvimento, Indústria e Comércio Exterior. Brasília - DF, 2012. Disponível em :http//www.mdic.gov.br./artigos/dwnl_1347644592.pdf. Acesso em 16/04/13.

SANTOS, E. T. Exportações de Artesanato do Ceará no período de 2004 a 2006: Desafios e Oportunidades. Dissertação de Mestrado. Universidade de Fortaleza - UNIFOR. Fortaleza - CE, 2007. Disponível em: Erro! A referência de hiperlink não é válida. 55DE30383257536006290BF/\$File/NT0003DA8E.pdf>. Acesso em 24/04/2013.

SEBRAE. Termo de referência: Atuação do Sistema SEBRAE no Artesanato Brasileiro. Brasília. 2010. Disponível em:

Ciência e Sustentabilidade - CeS | Juazeiro do Norte v. 2, n. 1, p. 124-148, jan/jun 2016 
http://www.biblioteca.sebra.com.br/bds.BDS.nsf/.../NT00043F22.pdf. Acesso em: 18/04/ 2012.

SOUSA, R. A. V. Os artesãos e a economia do cariri: O caso da Associação mãe das dores de Juazeiro do Norte - CE. 2010. Monografia (graduação em Ciências Econômicas) - Universidade Regional do Cariri - URCA.

VALE, C. A. R. Catálogo do Artesanato Caririense: Juazeiro do Norte, Crato, Barbalha e Caririaçu - vol.1. Juazeiro do Norte: BSG, 2012. Ed. LIEGS

\section{APÊNDICE A \\ ROTEIRO DE ENTREVISTA I (Entrevista com os presidentes da Associação)}

\section{I - DADOS PESSOAIS}

1. Idade: ( ) entre 25 e 35 ( ) entre 36 e 45 ( ) entre 46 e 60 ( ) mais de 60.

2. Gênero sexual: ( ) Masculino ( ) feminino.

3. Nível de escolaridade: ( ) Analfabeto ( ) Fundamental Completo ( ) Fundamental Incompleto ( ) Ensino Médio Completo ( ) Ensino Médio Incompleto ( )Superior Completo ( ) Superior Incompleto ( ) Pós-Graduado II - ASSOCIAÇÃO

1. Há quanto tempo existe a associação? Quais os propósitos da associação em relação aos seus associados?

2. A associação tem apoio de outras instituições? Quais? De que forma isso ocorre?

3. Houve melhoria no crescimento da produção e da qualidade do artesanato decorrente desse apoio? Quais?

4. Como a associação se mantem financeiramente?

5. Quais as principais dificuldades da associação?

6. Na sua visão, qual a contribuição da associação para o desenvolvimento do setor artesanal de Juazeiro do Norte-CE?

7. Há algum projeto para a expansão do artesanato através dessa associação?

8. O que mais gostaria de acrescentar? Elogios, críticas.

\section{APÊNDICE B \\ ROTEIRO DE ENTREVISTA II (Entrevista com os Associados)}

I - DADOS PESSOAIS

1. Idade: ( ) entre 25 e 35 ( ) entre 36 e 45 ( ) entre 46 e 60 ( ) mais de 60.

2. Gênero sexual: ( ) Masculino ( ) feminino.

3. Nível de escolaridade: ( ) Analfabeto ( ) Fundamental Completo ( ) Fundamental Incompleto ( ) Ensino Médio Completo ( ) Ensino Médio Incompleto ( )Superior Completo ( ) Superior Incompleto ( ) Pós-Graduado II - ENTREVISTA 
1. Com que tipo de artesanato você trabalha? Há quanto tempo?

2. Com quem aprendeu este ofício?

3. Qual a importância do artesanato em sua vida? O que o artesanato the trás como benefício?

4. Quanto dinheiro você geralmente recebe pela venda dos seus produtos em um mês?

5. Você se mantém só com a venda desses produtos, ou tem outra atividade?

6. Há quanto tempo você participa da associação? O que a associação trás de beneficio para você?

7. Para quem você vende os produtos?

8. Quais as principais dificuldades que você enfrenta para produzir e vender seus produtos?

9. O que deveria mudar na associação para que as coisas ficassem melhores? 